\title{
ESTRUTURA DA COMUNIDADE FITOPLÂNCTÔNICA NA BAÍA DE TAMANDARÉ (PERNAMBUCO, NORDESTE DO BRASIL)
}

\author{
Michelle ROSEVEL DA SILVA ${ }^{1}$ \\ Maria da Glória Gonçalves da SILVA-CUNHA ${ }^{1}$ \\ Fernando Antônio do Nascimento FEITOSA ${ }^{1}$ \\ Kátia MUNIZ ${ }^{1}$
}

${ }^{1}$ Departamento de Oceanografia da UFPE. Av. Arquitetura, s/n, Cidade Universitária- CEP 50.670901 - Recife - Pernambuco - Brasil. michelleoceano@hotmail.com

Recebido: $13 / 05 / 2005$

Aceito: 09/09/2005

\section{RESUMO}

A comunidade fitoplanctônica na fração do microfitoplâncton foi estudada na Baía de Tamandaré, localizado a $110 \mathrm{~km}$ ao sul de Recife (Pernambuco, Brasil) durante o período de fevereiro/98 a janeiro/99 em dois ciclos de marés. O presente estudo objetiva analisar a estrutura da flora e determinar a variação espacial e temporal. As amostras foram obtidas através de arrastos superficiais horizontais com rede de plâncton com malha de $64 \mu \mathrm{m}$. Foram aferidos in situ dados sobre as variáveis abióticas: profundidade local, temperatura e transparência da água e, concomitantemente, coletadas amostras de água com garrafa do tipo Nansen para análise dos demais descritores. Foram inventariados 101 táxons, distribuídos entre as diatomáceas, cianofíceas, dinoflagelados, clorofíceas e euglenofíceas, seqüenciados em ordem de riqueza taxonômica e abundância, destacando-se as espécies Aulacodiscus kittoni Arnott, Cerataulus turgidus Ehrenberg, Chaetoceros lorenzianus Grunow, Coscinodiscus centralis Ehrenberg, Oscillatoria erytraeum Ehrenberg e Synechococcus elongatus (Nägeli) Nägeli. No período de estiagem, constatou-se maior número de espécies e densidade fitoplanctônica. Em relação aos parâmetros abióticos, a temperatura e salinidade da água, fosfato e silicato tiveram seus maiores valores no período de estiagem. $\mathrm{O} \mathrm{pH}$, oxigênio dissolvido, saturação e DBO não mostraram grandes variações sazonais, enquanto os teores mais elevados de nitrito, nitrato e material em suspensão foram registrados no período chuvoso, caracterizando o ecossistema costeiro estudado como livre de estresse ambiental, demonstrando alto grau de complexidade.

Palavras chaves: comunidade fitoplanctônica, estrutura, sucessão, Baía de Tamandaré.

Structure of phytoplankton community in Tamandaré Bay (Pernambuco, Northeast of Brasil)

\section{ABSTRACT}

Phytoplanktonic community was studied in Tamandaré Bay, located $100 \mathrm{~km}$ south from Recife (Pernambuco State, Northeastern Brazil) during the period to February/98 from January/99 comprehending two tidal cycles (low and high tides). The aim of this present study has analysed the floral structure and to determinate spacial and seasonal variation. Samples were collected on a 3minute superficial horizontal tow using plankton net $(64 \mu \mathrm{m}$ mesh). Data on the abiotic variables were gauged in situ: local depth, water temperature and transparency, and water samples were

Tropical Oceanography, Recife, v. 33, n. 2, p. 163-181, 2005. 
concomitantly collected with Nansen bottles for further analysis of other descriptors. An inventory was carried out with 101 taxa distributed among diatoms, blue-green algae. dinoflagellates, green algae and euglenoids, sequenced in order of taxonomic richness and abundance, standing out the species Aulacodiscus kittoni Arnott, Cerataulus turgidus Ehrenberg, Chaetoceros lorenzianus Grunow, Coscinodiscus centralis Ehrenberg, Oscillatoria erytraeum Ehrenberg e Synechococcus elongatus (Nägeli) Nägeli. Phytoplankton richness and density were higher during the dry period. Temperature, salinity, phosphate and silicate levels were higher during the dry period. Dissolved oxygen, $\mathrm{pH}$, saturation and BOD levels showed no great seasonal variation. While the higher nitrite, nitrate and suspended solids levels were recorded during the rainy period. The data obtained classifying the studied coastal ecosystems as free from environmental stress, demonstrating high complexity levels.

Keywords: phytoplanktonic community, structure, sucession, Tamandare Bay

\section{INTRODUÇÃO}

A comunidade fitoplanctônica representa a base da teia alimentar dos ambientes aquáticos e tem merecido bastante atenção, sendo considerada por diversos pesquisadores como um dos principais produtores desses ecossistemas. Tal afirmativa decorre do papel exercido pelos organismos fitoplanctônicos ao produzir a matéria orgânica inicial que permitirá o funcionamento da quase totalidade das teias alimentares, sustentando, assim, os demais níveis tróficos.

Esta comunidade é basicamente formada por microalgas representadas, principalmente, pelas cianofíceas (Cyanophyta), euglenofíceas (Euglenophyta), dinoflagelados (Pyrrophyta), diatomáceas (Chrysophyta) e algumas clorofíceas (Chlorophyta), apresentando-se de forma isolada, colonial ou filamentosa, podendo ter hábitos flutuantes (planctônicas), estarem aderidas a diversos substratos (epifitas, epizóicas, epipélicas, epilíticas, etc.), ou vivendo diretamente em contato com o sedimento do fundo (bentônicas) (HOEK et al., 1995).

Além de constituir uma comunidade bastante heterogênea, a complexidade das microalgas também está relacionada às diversidades de formas, adaptações e, principalmente, dimensões, podendo-se enquadrá-las em quatro grupos quanto aos padrões de dimensão: picoplâncton $(0,2-$ $2,0 \mu \mathrm{m})$, constituído pelas cianobactérias; nanoplâncton $(2,0-20,0 \mu \mathrm{m})$, representado por organismos flagelados de pequena dimensão; microplâncton $(20,0-200 \mu \mathrm{m})$, composto pelas algas eucariotas e do mesoplâncton (0,2-20,0mm), compostos de grandes diatomáceas (BONEY, 1989).

Esses organismos têm modificado a atmosfera terrestre por mais de 2,7 bilhões de anos e continuam exercendo uma forte influência na composição química da atmosfera e nos ciclos biogeoquímicos do carbono, enxofre, nitrogênio, fósforo e outros elementos (BUICK, 1992).

Em seu conjunto, as microalgas são de vital importância para os ecossistemas marinhos, e mudanças em sua composição e estrutura podem ocasionar profundas modificações em todos os níveis tróficos, apresentando um caráter muito dinâmico, com elevadas taxas de reprodução e perda, respondendo rapidamente às alterações físicas e químicas do meio aquático e estabelecendo complexas relações intra e interespecíficas na competição e utilização do espaço e dos recursos (VALIELA, 1995).

Desta forma, o presente trabalho objetiva analisar a estrutura da comunidade microfitoplanctônica da Baía de Tamandaré e determinar a variação espacial e temporal, já que a área continua sendo considerada insuficientemente conhecida em relação aos estudos das algas, segundo o Atlas da Biodiversidade de Pernambuco (SECTMA, 2002). 


\section{MATERIAL E MÉTODOS}

As amostras de água analisadas para o presente estudo, tanto em relação ao fitoplâncton quanto os parâmetros abióticos, foram procedentes de coletas mensais e superficiais, durante as preamares e baixa-mares de um mesmo dia, no período de fevereiro de 1998 a janeiro de 1999, na Baia de Tamandaré, município de Tamandaré (Fig. 1).

\section{Área de estudo}

Tamandaré está localizada no litoral Sul do estado de Pernambuco, a $110 \mathrm{~km}$ da cidade do Recife, entre as coordenadas geográficas $08^{\circ} 45^{\prime} 36^{\prime \prime}$ e $08^{\circ} 47^{\prime} 20^{\prime \prime} \mathrm{S}$ e $35^{\circ} 03^{\prime} 45^{\prime \prime}$ e $35^{\circ} 06^{\prime} 45^{\prime \prime} \mathrm{W}$ (Fig.1). Possui aproximadamente $9 \mathrm{~km}$ de costa dividida em três áreas: Praia dos Carneiros, Praia dos Campas e a Baía de Tamandaré.

O clima da região é do tipo litorâneo, apresentando-se tipicamente quente e úmido do tipo AS', segundo o sistema de classificação de Köppen, caracterizado por um período chuvoso e um período de estiagem.

A precipitação pluviométrica anual na faixa costeira de Pernambuco oscila em torno dos $2.000 \mathrm{~mm}$, sendo as frentes frias, as brisas e as ondas de leste os principais sistemas meteorológicos que influenciam as chuvas na região. O período de estiagem se estende de setembro a março, quando mais de $95 \%$ da precipitação fica abaixo dos $400 \mathrm{~mm}$. Já o período chuvoso se estende de abril a agosto, no qual ocorrem 70 a $75 \%$ das chuvas totais (LIMA, 2001).

A temperatura média anual do ar varia entre 25 e $30^{\circ} \mathrm{C}$, sendo fortemente influenciada pela ação moderada dos ventos alísios, que sopram de SE e NE (MOURA, 1991).

Para a realização do presente estudo, foi determinado um ponto de coleta na porção da Baía de Tamandaré que recebe influência do estuário formado pelos rios Ilhetas e Mamucaba, localizados ao sul, sendo de grande importância na fertilização de suas águas.

A Baía de Tamandaré é uma reentrância na costa formada em decorrência de estrutura de falhamento, típico de litorais Atlântico (GUERRA, 1969). Apresenta uma forma semi-circular, demonstrando a forte ação do mar na sua morfologia (REBOUÇAS, 1965/66). Possui 4km² de extensão e profundidade média em torno de $7 \mathrm{~m}$. Limita-se ao norte, com o "Pontal do Lira"; ao sul, com a Ponta do Mamucabinha; a leste, com a linha de recifes e a oeste, com a linha de praia.

Apresenta uma faixa recifal com grande influência na sua hidrodinâmica, em decorrência da formação de uma espécie de barreira que impede a intensidade e a direção dos ventos e as correntes de marés (MOURA, 1991). Evidenciam-se três grupos de formações recifais: a primeira linha recifal, próxima à praia, constituída de estruturas arenosas e expostas durante a baixa-mar; a segunda, localizada na lagoa entre a linha de praia e a de recifes; e a última linha recifal forma uma barreira típica do complexo Tamandaré (NASCIMENTO-VIEIRA, 2000).

Além do ponto de vista náutico, a baía é conhecida pelos registros de florações periódicas de microalgas planctônicas em suas águas, conhecido na região por Tingüi, ocasionado pela cianobactéria Oscillatoria erythraeum (Trichodesmium erythraeum), que afeta a população local, sendo denominado de "Febre de Tamandaré" (SATÔ et al., 1963/64).

De acordo com o Decreto Federal de outubro de 1997, o complexo recifal de Tamandaré encontra-se inserido na Área de Proteção Ambiental (APA - Costa dos Corais), a primeira criada para os recifes costeiros no Brasil, sendo considerada a maior Unidade Federal de Conservação Marinha do país. 


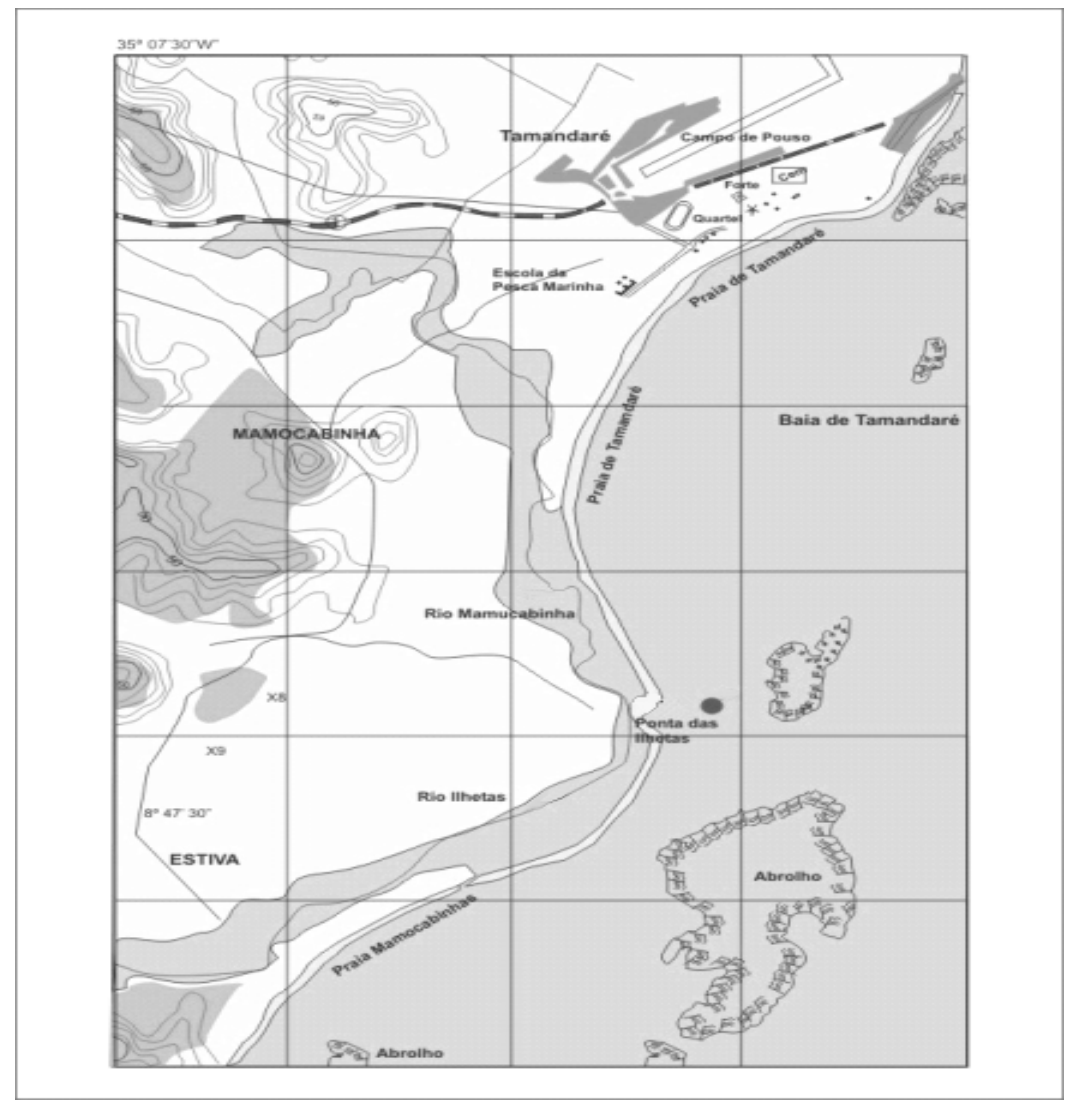

Figura 1 - Área de Tamandaré, Pernambuco, Nordeste do Brasil.

\section{Procedimento de campo}

As amostras do fitoplâncton foram coletadas com rede de plâncton, $64 \mu \mathrm{m}$ de abertura de malha, arrastadas horizontalmente à superfície por 3 minutos e, posteriormente, fixadas com formol neutralizado a $4 \%$.

Os dados pluviométricos foram procedentes do Instituto Pernambucano de Agropecuária (IPA) e da Secretaria de Ciência, Tecnologia e Meio Ambiente.

Em relação à análise dos parâmetros abióticos, alguns foram aferidos in situ e outros coletados com garrafa de Nansen, os quais foram analisados pela Seção de Química do Departamento de Oceanografia da UFPE: profundidade local (ecossonda manual digital), transparência da água (disco de Secchi) e coeficiente de extinção da luz (POOLE e ATKINS, 1929), temperatura da água (termômetro de reversão acoplado à garrafa), salinidade (refratômetro manual), Potencial Hidrogeniônico $(\mathrm{pH})$ (potenciômetro Beckman Zeromatic II), oxigênio dissolvido (método de Winkler descrito por STRICKLAND e PARSONS, 1972), teor de saturação do oxigênio dissolvido (UNESCO, 1973), Demanda Bioquímica do Oxigênio (DBO) (APHA, 1965), nutrientes nitrito, nitrato e fostato (métodos descritos por STRICKLAND e PARSONS. 1972), silicato (GRASSHOFF et al., 1983) e material em suspensão (MELO et al., 1975).

\section{Procedimento de laboratório}

Tropical Oceanography, Recife, v. 33, n. 2, p. 163-181, 2005. 
Foi realizada a análise quali-quantitativa das amostras de fitoplâncton, em câmara Sedgwich-Rafter de $1 \mathrm{~mL}$, com o auxílio do microscópio óptico. A identificação taxonômica, enquadramento dos táxons e reconhecimento dos dados ecológicos foram baseados nas literaturas especializadas (HUSTEDT, 1930; CUPP, 1943; DESIKACHARY, 1959; HUSTEDT, 1959, 19611966; HENDEY, 1964; PERÁGALLO E PERÁGALLO, 1965-1967; BALECH, 1988; HEURCK, 1986; SILVA-CUNHA E ESKINAZI-LEÇA, 1990; MOREIRA-FILHO, 1990).

Após a identificação dos táxons, foi realizada a contagem do número de células de cada amostra, calculando-se, ao final, o número total de células de cada táxon de acordo com a seguinte fórmula: $\mathrm{N}=\mathrm{Vt} . \mathrm{x} / \mathrm{Vc}$, onde: $\mathrm{Vt}=$ volume total de diluição, $\mathrm{x}$ = número de células de cada táxon, na subamostra, $\mathrm{Vc}=$ volume da subamostra.

$\mathrm{O}$ número total de células por unidade de volume foi obtido pela seguinte fórmula: $\mathrm{N}^{\mathrm{O}}$ cel. $\mathrm{L}^{-1}=\mathrm{N} / \mathrm{V}$, onde: $\mathrm{N}=$ número total de cada táxon na amostra, $\mathrm{V}=$ volume de água filtrada, onde $\mathrm{V}=\mathrm{A} \mathrm{X} \mathrm{d}\left(\mathrm{A}=\right.$ área da boca da rede de plâncton $\left(\pi \cdot \mathrm{r}^{2}\right), \mathrm{d}=$ distância percorrida pelo barco $=$ velocidade do barco $\mathrm{X}$ tempo de arrasto).

\section{Tratamento dos dados}

Os dados obtidos foram tratados numérica e estatisticamente. A abundância relativa e freqüência de ocorrência de cada táxon foram baseadas segundo Lobo e Leighton (1986) e Mateucci e Colma (1982), respectivamente. Para cada amostra, foi calculado o índice de Diversidade Específica (bits.cel ${ }^{-1}$ ) utilizando-se o índice de Shannon (1948).

As análises multivariadas da estrutura da comunidade microfitoplanctônica ao longo do ano foram realizadas com base na matriz de densidade fitoplanctônica, utilizando os índices de dissimilaridade de Bray e Curtis. A classificação para obtenção do dendrograma foi a do peso proporcional WPGMA (Weighted Pair Group Method Avarage Arithmetics). A Análise dos Componentes Principais (ACP) foi realizada através de uma matriz de dados da densidade das espécies mais abundantes e os parâmetros ambientais, utilizando o coeficiente de correlação momento-produto de Pearson, sendo em seguida extraídos o autovetor e o autovalor. Para estas análises foi utilizado programa computacional NTSYS (Numerical Taxonomy and Multivariate Analysis System) da Metagraphics Software Corporation, California - USA.

\section{RESULTADOS}

\section{Estrutura da comunidade}

Na Baía de Tamandaré foi registrado um total de 101 táxons, distribuídos entre as divisões Bacillariophyta, com 81,18\%; Cyanophyta, com 7,92\%; Dinophyta, com 6,93\%; Chlorophyta, com 2,97\% e Euglenophyta, com 1,00\% dos táxons inventariados (Tab. 1).

Esse levantamento florístico evidenciou claramente a predominância das diatomáceas no complexo costeiro. Os demais grupos de microalgas constituíram os componentes de menor representatividade, porém de grande relevância para o incremento da flora local.

A riqueza taxonômica oscilou de 8 a 27 táxons, o mínimo registrado na preamar de março/98 e o máximo na baixa-mar do mês de fevereiro/98, respectivamente. Em relação às marés, constatou-se que nas baixa-mares foi encontrado o maior número de táxons quando comparado os das preamares. No aspecto sazonal, observou-se um maior número de táxons no período de estiagem do que no período chuvoso, principalmente na baixa-mar (Fig. 2).

Quanto à densidade microfitoplanctônica, o valor mínimo registrado foi de 2,22Cel.L $\mathrm{L}^{-1} \mathrm{em}$ março/98 na preamar e o máximo de $84,87 \mathrm{Cel} . \mathrm{L}^{-1}$ no mês de abril/98 no momento de baixa-mar. Durante as baixa-mares, a densidade oscilou de $7,58 \mathrm{Cel} . \mathrm{L}^{-1}$ registrada no mês de novembro/98 a $84,87 \mathrm{Cel} . \mathrm{L}^{-1}$ encontrada em abril/98. Nas preamares, os valores mínimo e máximo foram, respectivamente, 2,22Cel. $\mathrm{L}^{-1}$ em março/98 e 45,86Cel. $\mathrm{L}^{-1}$ em janeiro/99 (Fig. 3). 
Tabela 1 - Inventário florístico das espécies fitoplanctônicas registradas na Baía de Tamandaré, Pernambuco, Nordeste do Brasil.

\section{CYANOPHYTA}

Merismopedia elegans Smith

Merismopedia punctata Meyer

Synechococcus elongatus Nägeli

Phormidium sp.

Spirulina sp.

Oscillatoria erythraeum Ehrenberg

= Trichodesmium erytraeum

Ehrenberg

Anabaena sp.

Nostoc sp.

\section{EUGLENOPHYTA}

Euglena sp.

\section{DINOPHYTA}

Dinophysis caudata Saville Kent

Dinophysis tripos Gourret

Pyrophacus sp.

Ceratium pentagonum Gourret

Ceratium trichoceros (Ehrenberg)

Kofoid

Ceratium tripos (Müller) Nitzsch

Ceratocorys armata (Schütt) Kofoid

\section{BACILLARIOPHYTA}

Thalassiosira leptopus (Grun) Hasle e Frywell

= Coscinodiscus lineatus Ehrenberg

Thalassiosira subtilis (Ostenfeld)

Balech

Thalassiosira sp.

Melchersiella hexagonalis C.

Teixeira

Melosira dubia Kützing

Paralia sulcata (Ehrenberg) Cleve

$=$ Melosira sulcata (Ehrenberg)

Kützing

Coscinodiscus centralis Ehrenberg

Coscinodiscus oculus iridis

Ehrenberg

Coscinodiscus sp.

Aulacodiscus kittoni Arnott

Triceratium antediluvianun (Ehr.)

Grunow

Triceratium dubia Brightwell

= Biddulphia dubia (Brightwell)

Cleve

Triceratium pentacrinus Ehrenberg

Triceratium shadboltianum Greville Triceratium sp.
Odontella longicruris (Greville) Holan

Odontella aurira (Lyngb.) Agardh

= Biddulphia aurita (Lyngb.) Brèb. e

Godey

= Biddulphia longicruris Greville

Odontella mobiliensis (Bailey) Grunow

= Biddulphia mobiliensis Grunow

Odontella rhombus (Ehrenberg)

Kützing

= Biddulphia rhombus (Ehrenberg)

Smith

Eupodiscus antiqüus (Cox) Hanna

Cerataulus smithii Ralph in Pritchard

Cerataulus turgidus Ehrenberg

Auliscus caelatus (Bailey) Clever Euler

Plagiogramma pulchellum Greville

Biddulphia biddulphiana Smith

= Biddulphia puchella Gray

Biddulphia sp.

Biddulphia tridens Ehrenberg

= Biddulphia tuomeyii (Bailey) Roper

Isthmia enervis Ehrenberg

Terpsinoe musica Ehrenberg

Bellerochea malleus (Brightwell) Van

Heurck

Heliotheca thamensis (Shrubsole)

Ricard

= Streptotheca thamensis Shrubsole

Lithodesmium undulatum Ehrenberg

Ditylum brightwell (West.) Grunow

Rhizosolenia setigera Brightwell

Rhizosolenia styliformis Brightwell

Chaetoceros affinis Lauder

Chaetoceros curvisetus Cleve

Chaetoceros lorenzianus Grunow

Chaetoceros sp.

Chaetoceros teres Cleve

Fragilaria capucina Desmazières

Fragilaria sp.

Diatoma elongatum Lyngbye (Agardh)

Synedra affinis Kützing

Synedra gailloni (Bory) Erhenberg

Podocystis adriatrica Kützing

Toxarium undulatum Bailey

= Synedra undulata Bailey

Thalassionema nitzschioides Grunow

Rhabdonema adriatricum Kützing

Rhabdonema punctatum (Harvey e

Barley) Stodder

Striatella interrupta (Ehr.) Heiberg
Striatella unipunctata (Lyngbye) Agardh Grammatophora marina (Lyngbye)

Kützing

Grammatophora oceanica Ehrenberg

Climacosphenia elongata Bailey

Climacosphenia moniligera (Lyngbye)

Kützing

Lyrella clavata (Gregory) Mann

= Navicula clavata Gregory

Lyrella lyra (Ehrenberg) Karayeva

= Navicula lyra Ehrenberg

Petroneis granulata (Bailey) D. G. Mann

= Navicula granulata (Bailey)

Petroneis humerosa Brébisson ex Wm.

Smith

= Navicula humerosa Brébisson

Achnanthes brevipes Agardh

Campyloneis grevillei (Smith) Grunow

Pinnularia trevelyana (Donkin) Cleve

= Navicula trevelyana (Donkin)

Rabenhorst

Pinnularia viridis (Nitzsch) Ehrenberg

Diploneis bombus Ehrenberg

Diploneis sp.

Navicula sp.

Pleurosigma angulatum Smith

Pleurosigma elongatum Smith

Pleurosigma sp.

Gyrosigma balticum (Ehrenberg) Cleve

Bacillaria paxillifera (O. F. Müller)

Hendey

= Bacillaria paradoxa Gmelin

Nitzschia longissima (Brèbisson) Grunow

Nitzschia sigma (Kützing) Wm. Smith

Nitzschia sp.

Cylindrotheca closterium (Ehrenberg)

Reiman Lewis

= Nitzschia closterium (Ehr.) Smith

Amphiprora paludosa. var. duplex (Smith)

Donkin

Amphiprora sp.

Surirella fastuosa Ehrenberg

Campylodiscus ecclesianus Greville

Campylodiscus fastuosus Ehrenberg

= Campylodiscus thuretti Brébisson

Campylodiscus sp.

\section{CHLOROPHYTA}

Pleodorina sp.

Micrasterias radians Turner

Cladophora sp. 


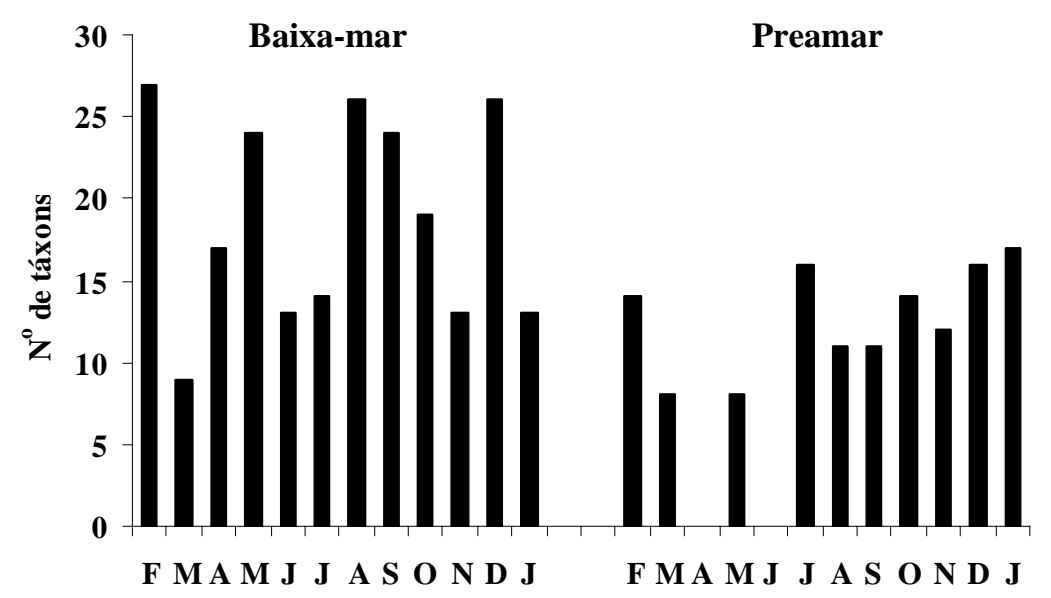

Figura 2 - Riqueza taxonômica da comunidade microfitoplanctônica na Baía de Tamandaré, Pernambuco, Nordeste do Brasil.

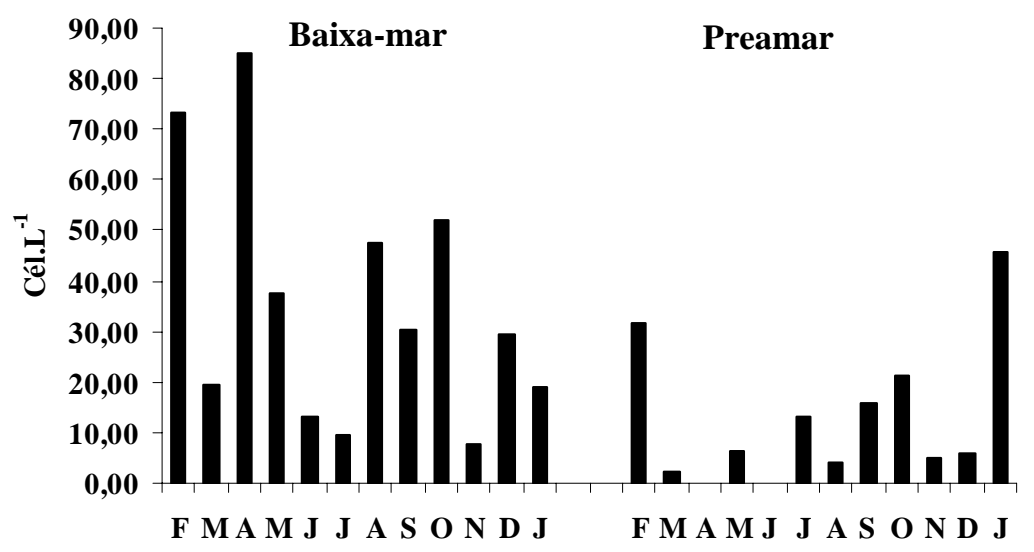

Figura 3 - Densidade microfitoplanctônica $\left(\right.$ Cel. $\left.L^{-1}\right)$ na Baía de Tamandaré, Pernambuco, Nordeste do Brasil.

Foi possível observar maiores valores de densidade durante o regime de baixa-mar do que preamar.Analisando de uma perspectiva sazonal, contatou-se que durante a baixa-mar não houve diferenças sazonais. Já na preamar, os valores de densidade foram mais elevados no período de estiagem.

Dentre os táxons inventariados, as diatomáceas que se destacaram na área em questão foram Chaetoceros lorenzianus e, especialmente, Coscinodiscus centralis espécies predominantes que contribuíram com o incremento da flora com 82,35\%, em abril/98 e 61,82\%, em setembro/98, no momento de baixa-mar, respectivamente. A cianobactéria Synechococcus elongatus também dominou na área, contribuindo com $76,74 \%$ da abundância relativa dos táxons, em fevereiro/98 na preamar (Tab. 2).

Tropical Oceanography, Recife, v. 33, n. 2, p. 163-181, 2005. 
Tabela 2 - Abundância relativa (\%) dos principais táxons registrados no período de fevereiro/98 a janeiro/99 na Baía de Tamandaré, Pernambuco, Nordeste do Brasil.

\begin{tabular}{|c|c|c|c|c|c|c|c|c|c|c|c|c|c|}
\hline \multirow{3}{*}{ TÁXONS } & \multicolumn{13}{|c|}{ Período Chuvoso } \\
\hline & \multirow{2}{*}{$\begin{array}{l}\text { Mês } \\
\text { Maré }\end{array}$} & \multicolumn{2}{|c|}{ MAR } & \multicolumn{2}{|c|}{ ABR } & \multicolumn{2}{|c|}{ MAIO } & \multicolumn{2}{|c|}{ JUN } & \multicolumn{2}{|c|}{ JUL } & \multicolumn{2}{|c|}{ AGO } \\
\hline & & BM & PM & BM & PM & BM & $\mathbf{P M}$ & BM & $\mathbf{P M}$ & BM & PM & BM & $\mathbf{P M}$ \\
\hline \multicolumn{14}{|l|}{ BACILLARIOPHYTA } \\
\hline Chaetoceros lorenzianus & & & & 82,35 & & & & & & & & & \\
\hline Coscinodiscus centralis & & 59,43 & 8,33 & & & 50,00 & & & & & 49,30 & 39,45 & \\
\hline \multirow[t]{2}{*}{ Coscinodiscus sp.1 } & & & & 1,96 & & & 44,12 & 18,06 & & 21,57 & & & 21,74 \\
\hline & \multicolumn{13}{|c|}{ Período de Estiagem } \\
\hline \multirow[t]{2}{*}{ TÁXONS } & Mês & \multicolumn{2}{|c|}{ SET } & \multicolumn{2}{|c|}{ OUT } & \multicolumn{2}{|c|}{ NOV } & \multicolumn{2}{|c|}{ DEZ } & \multicolumn{2}{|c|}{ JAN } & \multicolumn{2}{|c|}{ FEV } \\
\hline & Maré & BM & PM & BM & PM & BM & PM & BM & PM & BM & PM & BM & PM \\
\hline \multicolumn{14}{|l|}{ CYANOPHYTA } \\
\hline Synechococcus elongatus & & & & & & & & & & & & & 76,74 \\
\hline \multicolumn{14}{|l|}{ BACILLARIOPHYTA } \\
\hline Coscinodiscus centralis & & 61,82 & 4,71 & 14,18 & 24,14 & 19,51 & 18,52 & 5,66 & 12,50 & 54,90 & 22,18 & 2,52 & \\
\hline Striatella sp. & & & & & & & & 55,97 & & & & & \\
\hline
\end{tabular}

A partir da avaliação quali-quantitativa das populações, foram selecionadas as principais entidades taxonômicas em função de um critério de abundância e/ou ocorrência $(>40 \%)$, correspondendo as espécies consideradas dominantes e abundantes, assim como muito freqüentes e freqüentes na Baía de Tamandaré.

Dentre as espécies de maior ocorrência merece destaque Coscinodiscus centralis, Aulacodiscus kittoni, Cerataulus turgidus e Oscillatoria erythraeum (Fig. 4).

Um padrão característico foi observado com a presença de Coscinodiscus centralis na totalidade dos meses estudados. No aspecto sazonal, a comunidade microfitoplanctônica apresentou uma diferenciação quanto à dominância de espécies nos dois períodos que caracterizam o litoral de Pernambuco (de estiagem e chuvoso).

No período de estiagem, a cianobactéria Synechococcus elongatus foi considerada dominante $(\geq 70 \%)$ no mês de fevereiro/98 durante o regime de preamar. A diatomácea Striatella sp. também contribuiu significativamente em dezembro/98 na baixa-mar, perfazendo $55,97 \%$ de abundância relativa. No mesmo período, a espécie Coscinodiscus centralis destacou-se, principalmente, nos meses de setembro/98 e janeiro/99, sendo considerada abundante na Baía de Tamandaré (Tab. 2). 

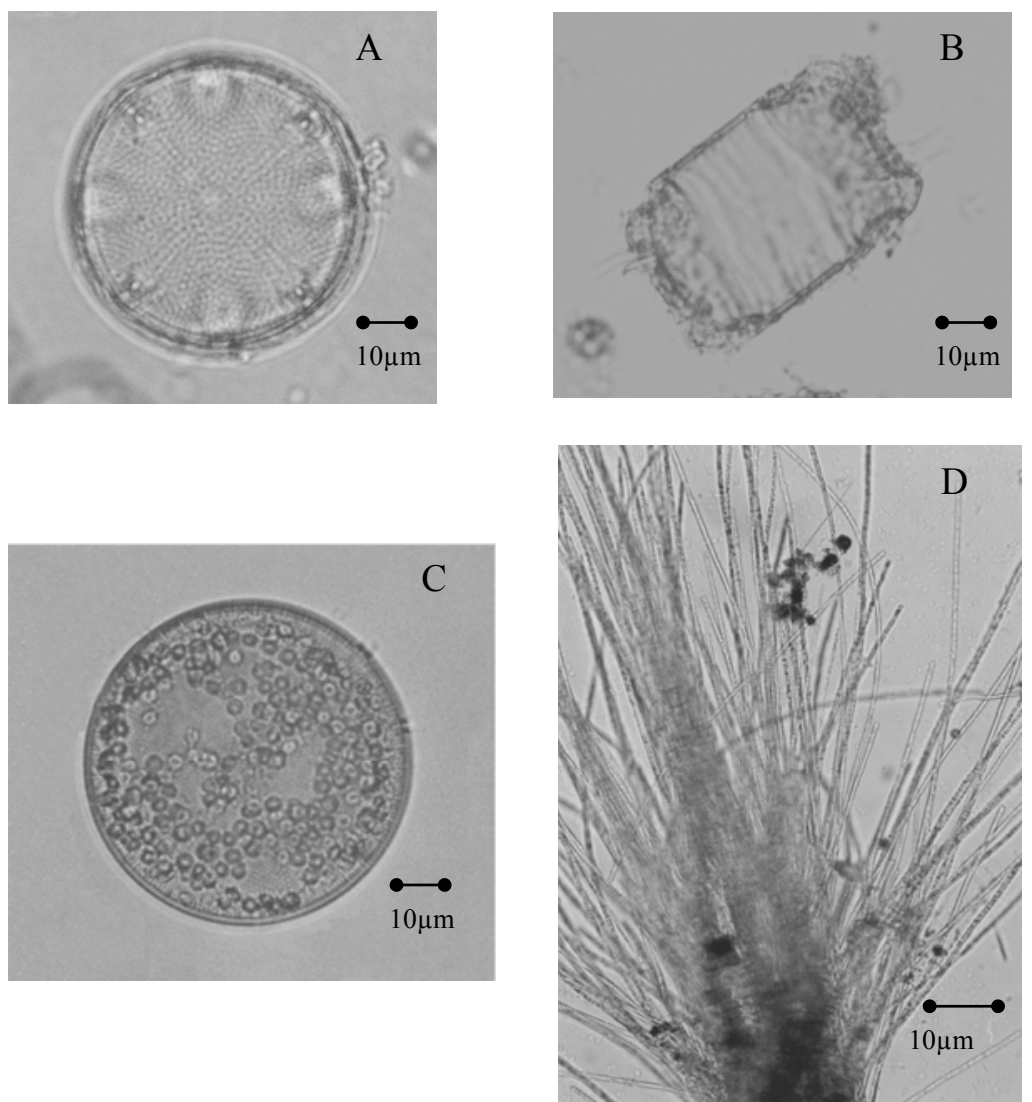

Figura 4 - Principais entidades taxonômicas do fitoplâncton na Baía de Tamandaré, Pernambuco, Nordeste do Brasil (A - Aulacodiscus kittoni, B - Cerataulus turgidus, C - Coscinodiscus centralis, D - Oscillatoria erytraeum).

Durante o período chuvoso, a comunidade fitoplanctônica foi incrementada com a presença das espécies tipicamente marinhas planctônicas: Chaetoceros lorezianus e Coscinodiscus centralis. A primeira espécie, classificada como dominante em abril/98, na baixa-mar, perfazendo $82,35 \%$ do total. Foi constatado, também, o reaparecimento de Coscinodiscus centralis, espécie em destaque nesse período, nos meses de março, maio e junho/98, corroborando a sua tolerância ao regime de salinidade (Tab. 2).

\section{Diversidade específica (bits.cel ${ }^{-1}$ )}

$\mathrm{Na}$ Baía de Tamandaré, a diversidade específica oscilou de 1,25 à 3,70bits.cel ${ }^{-1}$, caracterizando uma diversidade de baixa à alta, tendo sido valores registrados em abril/98 na baixamar e dezembro/98 na preamar. A baixa diversidade foi constatada em virtude da presença da espécie Chaetoceros lorenzianus que apresentou nesse período $82,35 \%$ de abundância relativa (Fig. 5) 


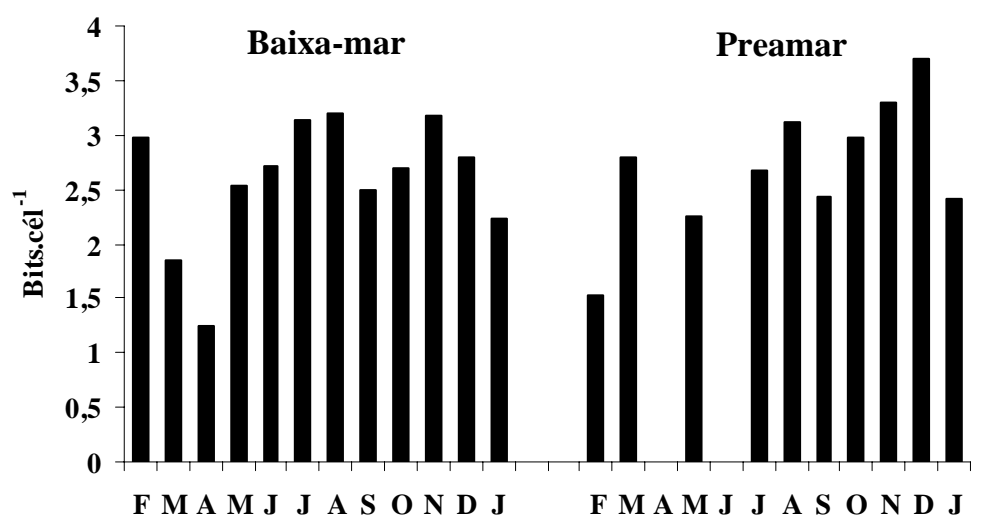

Figura 5 - Diversidade específica $\left(\right.$ bits.cel $^{-1}$ ) da comunidade microfitoplanctônica na Baía de Tamandaré, Pernambuco, Nordeste do Brasil.

\section{Associação de espécies}

A análise de agrupamento apresentou uma análise cofenética $(\mathrm{r}=0,89)$ bem ajustada, significando a ocorrência de dois grupos bem distintos (Fig. 6). O primeiro grupo formado por espécies muito freqüentes: Oscillatoria erythraeum, Aulacodiscus kittoni, Cerataulus turgidus, Coscinodiscus $\mathrm{sp}_{1}$ e Coscinodiscus centralis consideradas planctônicas oceânicas e ticoplanctônicas. $\mathrm{O}$ segundo grupo evidenciou as espécies Fragilaria capucina, Nitzschia $\mathrm{sp}_{1}$, Pleurosigma sp, Navicula sp e Terpsinoe musica, consideradas ticoplanctônicas e freqüentes na Baía de Tamandaré.

Figura 6 - Dendrograma das associações das espécies do microfitoplâncton mais representativas na Baía de Tamandaré, Pernambuco, Nordeste do Brasil.

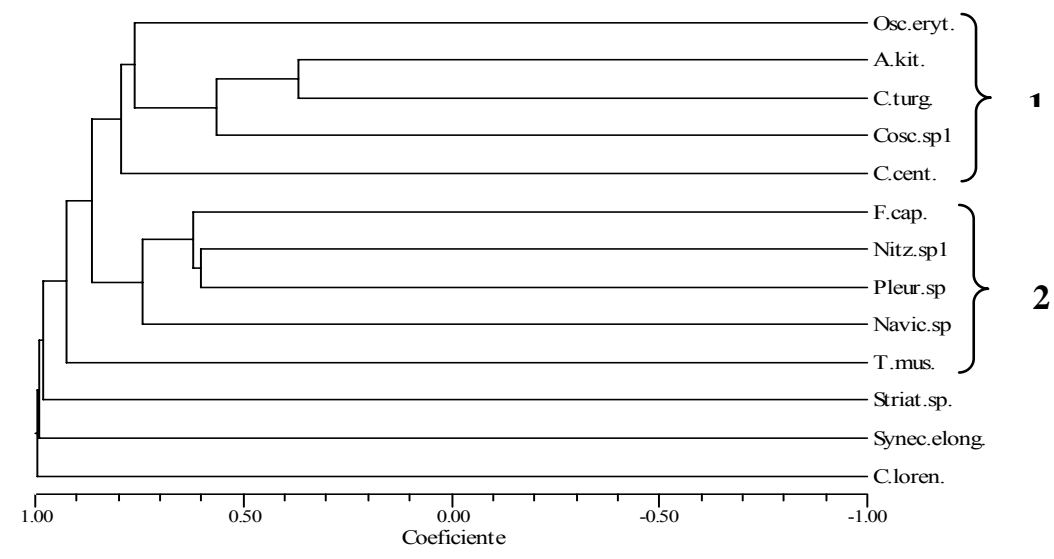

\section{Parâmetros abióticos}

A composição e distribuição da comunidade microfitoplanctônica é fortemente condicionada pelos fatores climatológicos e abióticos. Durante os anos de 1998 e 1999, constatou-se

Tropical Oceanography, Recife, v. 33, n. 2, p. 163-181, 2005. 
que o total de chuva mensal oscilou entre $9,9 \mathrm{~mm}$ no mês de novembro/98 e 212,2mm em agosto/98 (Fig. 7).

Os dados mínimos, máximos e médios dos parâmetros físico-químicos obtidos nas análises das amostras coletadas durante os ciclos de marés estão dispostos na tabela 3.

Figura 7 - Precipitação Pluviométrica da Baía de Tamandaré, Pernambuco, Nordeste do Brasil.

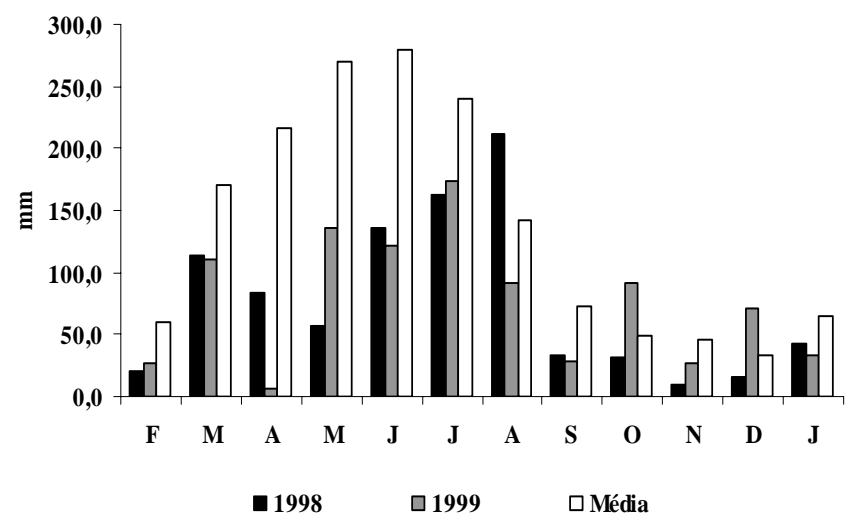

Tabela 3 - Dados hidrológicos da Baía de Tamandaré, Pernambuco, Nordeste do Brasil.

\begin{tabular}{|c|c|c|c|c|c|c|}
\hline Material em suspensão (mg.L $\left.{ }^{-1}\right)$ & 3,00 & Bdikgd-mar & 7,38 & 2,00 & Predhar & 4,88 \\
\hline Parameuros adioucos & Mín. & Máx. & Média & Mín. & Máx. & Média \\
\hline Profundidade local (m) & 5,20 & 6,70 & 5,91 & 6,00 & 8,00 & 7,37 \\
\hline Transparência da água (m) & 1,50 & 4,50 & 2,79 & 1,80 & 4,70 & 2,82 \\
\hline Coeficiente de extinção. Da luz (m) & 0,38 & 1,13 & 0,67 & 0,57 & 0,94 & 0,64 \\
\hline Temperatura da água $\left({ }^{0} \mathrm{C}\right)$ & 27,00 & 31,00 & 28,75 & 26,80 & 30,00 & 28,06 \\
\hline Salinidade da água & 30,00 & 36,00 & 32,92 & 32,00 & 35,00 & 33,82 \\
\hline pH & 8,02 & 8,65 & 8,28 & 7,90 & 8,54 & 8,24 \\
\hline Oxigênio dissolvido (ml.L $\left.\mathbf{L}^{-1}\right)$ & 4,48 & 5,65 & 5,17 & 3,81 & 5,63 & 4,92 \\
\hline $\begin{array}{l}\text { Percentual de saturação do Oxigênio } \\
\text { (\%) }\end{array}$ & 98,46 & 129,00 & 144,99 & 87,59 & 126,23 & 108,85 \\
\hline DBO (mg.L $\left.{ }^{-1}\right)$ & 0,10 & 1,22 & 0,51 & 0,00 & 0,83 & 0,26 \\
\hline Nitrito $\mathrm{NO}_{2}(\mu \mathrm{M})$ & 0,00 & 0,12 & 0,04 & 0,02 & 0,14 & 0,05 \\
\hline Nitrato $\mathrm{NO}_{3}(\mu \mathrm{M})$ & 0,00 & 1,73 & 0,84 & 0,08 & 3,74 & 1,15 \\
\hline Fosfato $\mathrm{PO}_{4}(\mu \mathrm{M})$ & 0,08 & 0,28 & 0,14 & 0,00 & 0,23 & 0,13 \\
\hline Silicato $\mathrm{SiO}_{2}(\mu \mathrm{M})$ & 3,72 & 43,20 & 20,24 & 3,72 & 53,03 & 19,03 \\
\hline
\end{tabular}


$\mathrm{Na}$ área estudada, constataram-se valores elevados de profundidade local, especialmente durante a preamar quando comparados aos sistemas estuarinos dos rios Ilhetas e Mamucaba. A transparência da água foi reduzida no período chuvoso, onde os valores de disco de Secchi não coincidiram com a profundidade local e o inverso foi observado em relação ao coeficiente de extinção da luz. As menores temperaturas da água foram registradas também no período de maior precipitação, apresentando uma amplitude térmica de $4^{\circ} \mathrm{C}$. Quanto à salinidade, foi possível constatar valores característicos de regiões costeiras (>30\%) não havendo grande variação salina, assim como, um discreto padrão sazonal com maiores valores no período de estiagem. $\mathrm{O}$ pH, por sua vez, manteve-se alcalino.

Em relação ao oxigênio dissolvido, o percentual de saturação e Demanda Bioquímica do Oxigênio (DBO), registraram-se maiores valores de oxigênio dissolvido e DBO durante a baixa-mar e de saturação acima de $100 \%$, principalmente, na preamar, caracterizando assim, a área como isenta de poluição.

No sistema em questão, as concentrações máximas de sais nutrientes $\left(\mathrm{NO}_{2}, \mathrm{NO}_{3}\right.$ e $\mathrm{PO}_{4}$, $\mathrm{SiO}_{2}$ ) caracterizam a Baía de Tamandaré com oligotrófica, apresentando-se em concentrações normais para esses ambientes. Foi possível verificar diferenças sazonais, com valores mais elevados no período de estiagem de fosfato e silicato e o inverso com os nutrientes nitrogenados e o material em suspensão total, considerados bastante reduzidos.

A Análise dos Componentes Principais (ACP) permitiu observar a contribuição das variáveis ambientais juntamente com a biológica nos dois componentes principais na Baía de Tamandaré, onde o fator 1 explicou 20,09 e o fator 2, 15,49 da variância total dos dados, caracterizando dois grupos. O primeiro grupo, englobando as espécies Cerataulus turgidus, Chaetoceros lorenzianus, Oscillatoria erythraeum e Synechococcus elongatus com parâmetros abióticos que caracterizaram maior influência limnética. $\mathrm{O}$ segundo, englobando Coscinodiscus centralis e Nitzschia $\mathrm{sp}_{1}$ e as variáveis características do fluxo marinho (Fig. 8).

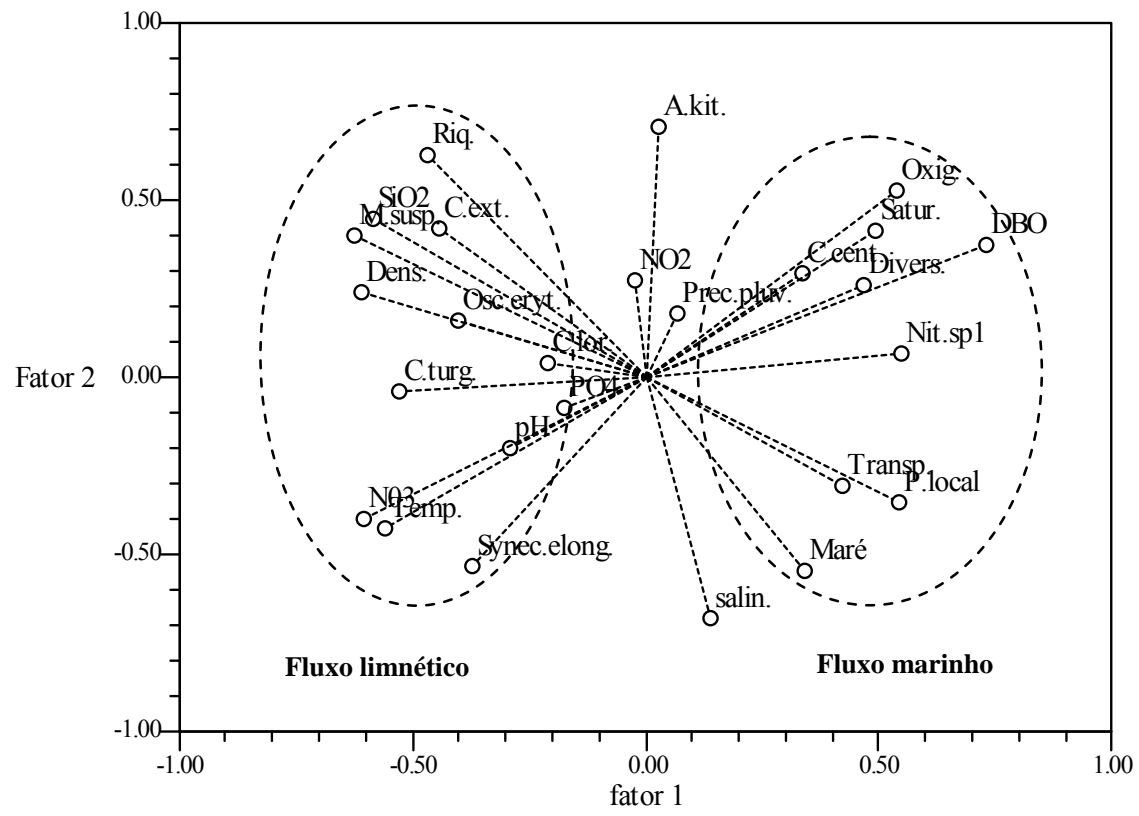

Figura 8 - Análise dos Componentes Principais (ACP) dos descritores abióticos e biológicos na Baía de Tamandaré, Pernambuco, Nordeste do Brasil. 


\section{DISCUSSÃO}

O estudo de microalgas para avaliação da qualidade de águas superficiais é cada vez mais utilizado, muitas razões podem ser apresentadas para justificar a utilização desses organismos no monitoramento dos ecossistemas aquáticos, como elevadas e rápidas taxas de reprodução assim como alta sensibilidade às alterações do meio.

Conhecendo as preferências ecológicas das espécies e aplicando esses conhecimentos às informações quali-quantitativas, diversidade e abundância, torna-se possível inferir o estado ecológico dos ecossistemas. Desta forma, as microalgas têm sido utilizadas como bioindicadoras da qualidade ambiental.

A comunidade microfitoplanctônica, constituída de diversos grupos, apresentou-se bastante diversificada na Baía de Tamandaré, englobando as divisões Bacillariophyta, Cyanophyta, Dinophyta, Chlorophyta e Euglenophyta. Uma confirmação mundial situa as diatomáceas como o grupo de microalgas mais importantes do fitoplâncton costeiro (DEVASSY e GOES, 1988; ESTRADA et al., 1999; PUIGSERVER et al., 2002). Esta, por sua vez, inclui o componente principal da flora marinha e uma significativa parte da flora de água doce, além das diatomáceas ticoplanctônicas encontradas em variados substratos, normalmente decorrente de grandes florescimentos em águas frias, porém, abundantes em águas tropicais (SILVA-CUNHA e ESKINAZI-LEÇA, 1990), bastante comuns em águas costeiras, por tolerarem grandes variações no conteúdo de sais dissolvidos.

Na Baía de Tamandaré, a dominância das diatomáceas foi constatada ao longo do ano, nos períodos sazonais e diferentes ciclos de marés, destacando-se as espécies Coscinodiscus centralis Ehrenberg, como a entidade taxonômica mais representativa, sendo este um fato comumente observado em águas costeiras do Nordeste brasileiro, em decorrência de uma melhor adaptação às condições reinantes (RILEY, 1967). Espécie em destaque nos estuários dos rios Ilhetas e Mamucaba, que deságuam na Baía de Tamandaré (ROSEVEL SILVA et al., 2004a) e na porção central do Canal de Santa Cruz (ROSEVEL SILVA et al., 2004b) localizados no litoral de Pernambuco.

Outra espécie dominante foi Chaetoceros lorenzianus, a qual caracteriza a flora das diatomáceas em outras áreas costeiras do estado de Pernambuco, como no estuário do rio Goiana (FEITOSA et al., 1999) e estuário do rio Ipojuca (KOENING et al., 2002), considerada espécie eurialina e encontrada em águas marinhas neríticas (ESKINAZI-LEÇA et al., 2004a).

Devido à natureza eurialina, Aulacodiscus kittoni, Cerataulus turgidus, Coscinodiscus centralis e Fragilaria capucina foram os táxons mais freqüentes que ocorreram no sistema estudado. Resultados da análise da associação de espécies (Cluster Analysis) confirmaram uma forte afinidade entre elas. Outras, como: Coscinodiscus $\mathrm{sp}_{{ }_{1}}$, Navicula $\mathrm{sp}_{{ }_{1},}$, Nitzschia $\mathrm{sp}_{{ }_{1}}$ e Pleurosigma sp. também contribuíram para essa representatividade.

As cianofíceas (cianobactérias) são também de fundamental importância na avaliação da qualidade dos sistemas aquáticos contribuindo com mais de $50 \%$ da biomassa e produção em oceanos tropicais oligotróficos e subtropicais abertos (AGAWIN et al., 2003). O estudo desses organismos também se faz de extrema importância, pois são as únicas entre as microalgas fotossintetizadoras que têm a habilidade de fixar nitrogênio. Esta habilidade proporciona para esse grupo uma vantagem competitiva em relação às algas e plantas que crescem em águas limitadas pelo nitrogênio, sendo este, um dos fatores que contribuem para o desenvolvimento excessivo dessas microalgas em águas doces e marinhas (GRAHAM e WILCOX, 2000).

No ambiente em questão, um reduzido número de espécies de cianobactérias contribuiu para o incremento da composição florística local, exceto Synechococcus elongatus e Oscillatoria erythraeum. O gênero Synechococcus também foi bastante representativo no sul do Mar da China, sendo considerado abundante em suas águas (AGAWIN et al., 2003). 
Atualmente, as pesquisas que vêm sendo desenvolvidas sobre as cianobactérias têm abordado problemas para a população humana associados à produção de toxinas pelas microalgas. Alguns trabalhos têm detectado a presença da Oscillatoria erythraeum (Trichodesmium erythraeum) como causadora de uma coloração atípica em suas águas, tais como o complexo estuarino MandoviZuari, na Índia (DEVASSY e GOES, 1988), no mar da Arábia Central (CAPONE et al., 1998) e em águas do Pacífico (DUPOUY et al., 2000).

Esta espécie foi considerada constante ao longo do período estudado na Baía de Tamandaré. Este fato já observado por Satô et al. (1963/64), onde os autores atribuíram a enorme capacidade de se multiplicar em águas com maior transparência.

Os demais grupos que compuseram a flora planctônica local apresentaram menor representatividade no sistema em questão, em virtude dos dinoflagelados habitarem preferencialmente as áreas oceânicas, enquanto, as clorofíceas e euglenofíceas encontram-se amplamente distribuídas em ambientes de água doce (BONEY, 1989).

Independente da dominância de alguns grupos, o número e distribuição dos táxons do microfitoplâncton associados ao número de células quantificados são fundamentais à caracterização dos ambientes aquáticos.

Diversos autores têm observado que as variações quantitativas ocorridas na riqueza e densidade microfitoplanctônica em mares tropicais estão mais relacionadas aos períodos anuais. Atribuem à precipitação pluviométrica grande importância, podendo influenciá-la direta ou indiretamente (KOENING e ESKINAZI-LEÇA, 1990), citado por diversos autores como controlador da distribuição e abundância do fitoplâncton, do padrão sazonal em águas costeiras, influenciando desta maneira outras variáveis abióticas (HUISMAN e WEISSING, 1999; FACCA et al., 2002). No entanto, é importante ressaltar que esse parâmetro foi considerado atípico para menos no período amostrado, mesmo assim, foi verificada uma marcada variação anual.

De acordo com Sournia (1969) e Tundisi $(1969,1986)$, as águas tropicais costeiras podem ou não apresentar um ciclo anual, dependendo ou não da ocorrência de modificações anuais em certos fatores ambientais, como ventos, correntes, precipitação, ressurgências costeiras, entre outros.

Essas alterações na qualidade da água refletem diretamente na estrutura da comunidade fitoplanctônica (BITTENCOURT-OLIVEIRA, 2002). Certas adaptações incluindo as mudanças fisiológicas, morfológicas e citológicas, permitem uma espécie ou grupo de espécies florescerem, levando ao fenômeno chamada sucessão (DEVASSY e GOES, 1986).

Além disso, essas modificações ambientais como competição, predação, diversidade de habitat, tempo e estabilidade ambiental interfere na diversidade de espécies (KREBS, 1985), podendo induzir a proliferação de espécies potencialmente tóxicas, refletindo na redução da qualidade da água com implicações econômicas, ecológicas e de saúde pública.

No sistema em questão, uma alta diversidade específica foi constatada, indicando que as espécies inventariadas estão distribuídas eqüitativamente no ambiente, demonstrando que o mesmo encontra-se bastante conservado, com um alto grau de complexidade.

Essa alta diversidade específica constatada na Baía de Tamandaré é também decorrente da heterogeneidade de espécies de origens diferentes, ou seja, água doce, marinha, estuarina e de hábitos perifíticos e bentônicos, a exemplo do que tem sido documentado por diversos pesquisadores em outras áreas já examinadas no litoral do Nordeste, diferindo de algumas áreas pela presença da maioria de espécies especialistas do que oportunistas, como foi registrado por Koening et al. (2002).

Assim, corrobora a importância da estabilidade ambiental no crescimento e fisiologia das algas e assim conseqüentemente a abundância fitoplanctônica, os quais devem estar funcionalmente adaptados a um conjunto de variáveis ambientais (MUKAI e TAKIMOTO, 1986; PHLIPS et al., 2002), conforme foi constatada na área estudada.

Dentre as variações físico-químicas, além das oscilações climáticas principalmente a precipitação pluviométrica, o regime de maré e a salinidade são as principais condicionantes da qualidade dos ecossistemas aquáticos.

Tropical Oceanography, Recife, v. 33, n. 2, p. 163-181, 2005. 
Como pôde ser comprovada na $\mathrm{ACP}$, verificou-se grupos com maior influência limnética (temperatura, nutrientes, material em suspensão) e marinha (maré, oxigênio dissolvido e seu percentual de saturação, profundidade local, transparência da água), que determinaram, também, a distribuição ecológica das espécies inventariadas, constatando a presença em destaque das marinhas planctônicas, assim como das estuarinas e dulciaquícolas de hábitos planctônicos e ticoplanctônicos.

Cabe ressaltar, ainda, a importância desses parâmetros adicionados aos indicadores da qualidade da água: oxigênio dissolvido, em condições de estagnação, os compostos orgânicos são utilizados por certas bactérias que obtêm o oxigênio, como também suas altas concentrações podem causar o fenômeno da eutrofização; Demanda Bioquímica do Oxigênio (DBO), freqüentemente influenciada por aportes naturais e antrópicos, que incrementam a quantidade de carga orgânica em águas costeiras e potencial hidrogeniônico $(\mathrm{pH})$, visto que está diretamente ligado à quantidade de dióxido de carbono e conseqüentemente de oxigênio dissolvido (THURMAN, 1997).

No entanto, faz-se importante o registro que a disponibilidade de energia luminosa, utilizada pelos organismos fitoplanctônicos para sintetizar de fontes inorgânicas $\left(\mathrm{CO}_{2} \mathrm{e}_{2} \mathrm{O}\right)$ compostos orgânicos de alta energia potencial e os sais nutrientes (nitrito, nitrato, fosfato e silicato) necessários ao crescimento e reprodução da comunidade algal, são limitantes para o crescimento algal que têm como produto final à liberação do oxigênio necessário à respiração (TUREKIAN, 1969).

Na Baía de Tamandaré, assim em outros sistemas costeiros, confirmou a interferência das variáveis ambientais na composição e distribuição da comunidade microfitoplanctônica, no entanto, os parâmetros indicadores da qualidade da água com as baixas concentrações dos componentes inorgânicos caracterizam a área em questão como oligotrófica e isenta de fortes impactos antrópicos.

\section{CONCLUSÃO}

A estrutura da comunidade fitoplanctônica foi bastante diversificada, determinada pela heterogeneidade ambiental, propiciando assim, uma maior diversidade da flora de ampla distribuição ecológica. As variáveis ambientais interferem diretamente na distribuição e composição da comunidade fitoplanctônica, evidenciando em termos de qualidade de água, um sistema costeiro que conserva suas condições naturais com alto grau de complexidade.

\section{AGRADECIMENTOS}

Agradecemos a Coordenação de Aperfeiçoamento de Pessoal em Nível Superior (CAPES), pela bolsa de estudos que viabilizou a realização desse trabalho, como parte constituinte da Dissertação de Mestrado em Oceanografia Biológica, desenvolvida no Departamento de Oceanografia da UFPE. Ao Centro de Pesquisa e Gestão de Recursos Pesqueiros do Litoral Nordeste (CEPENE), em nome do Dr. Antônio Clerton de Paula Pontes e Dr. Mauro Maida pelo apoio logístico na realização das coletas. A Msc. Ana Paula do Nascimento Losada, pela concessão das amostras de fitoplâncton para realização desse estudo.

\section{REFERÊNCIAS BIBLIOGRÁFICAS}

AGAWIN, N. S. R.; DUARTE, C. M.; AGUSTÍ, S.; McMANUS, L. Abundance, biomass and growth rates of Synechococcus sp. in a tropical coastal ecosystem (Philippines, South China Sea). Estuarine, Coastal and Shelf Science, London, v. 56, p. 493-502, 2003.

APHA. Standard methods for examination of water and wastewater. 16. ed. New York: [s.n.], 1985. $268 \mathrm{p}$.

Tropical Oceanography, Recife, v. 33, n. 2, p. 163-181, 2005. 
BALECH, E. Los dinoflagelados del Atlantico Sudoccidental. Madrid: Ministerio de Agricultura Pesca y Alimentacion, 1988. 310 p. (Publicaciones Especiales Instituto Español de Oceanografia, n. $1)$.

BITTENCOURT-OLIVEIRA, M. do C. A comunidade fitoplanctônica do rio Tibagi: uma abordagem preliminar de sua diversidade. In: MEDRI, M. E.; EDMILSON, B.; SHIBATTA, O. A.; PIMENTA, J. A. (Ed). A bacia do rio Tigabi. Londrina: M.E. Medri, 2002. 595 p. p. 373-402.

BONEY, A. D. Phytoplankton. 2 ed. London: Edward Arnold, 1989. 18-40 p.

BUICK, R. The antiquity of oxigenic photosyntesis. Evindence from stomatolites in sulphate deficient Archean lakes. Science. 255: 74-75, 1992.

CAPONE, D. G.; SUBRAMANIAM, A.; MONTOYA, J. P.; VOSS, M.; HOMBORG, C.; JOHANSEN, A. M.; SIEFERT, R. L.; CARPENTER, E. J. An extensive bloom of the N2-fixing cyanobacterium Trichodesmium erythraeum in the central Arabian Sea. Mar. Ecol. Prog. Ser., [S.1.], v. 172, 281-292, 1998.

CUPP, E. D. Marine plankton diatoms of the West Coast of North America. Los Angeles: University of California, 1943. 237 p. (Bulletin of the Scripps Institution of Oceanography, v. 6).

DESIKACHARY, T. V. Cyanophyta. New Delhi: Indian Council of Agricultural Research, 1959. 686 p. (I. C. A. R. Monographs on Algae).

DEVASSY, V. P.; GOES, J. I. Phytoplankton Community Structure and Succession in a Tropical Estuarine Complex (Central West Coast of India). Estuarine, Coastal and Shelf Science, London, v. 27, p. 671-685, 1988.

DUPOUY, C.; NEVEUX, J.; SUBRAMANIAM, A.; MULBOLLAND, M. R.; MONTOYA, J. P.; CAMPBELL, L.; CARPENTER, E. J.; CAPONE, D. G. Satellite captures Trichodesmium blooms in the southwestern tropical Pacific. EOS Trans. Am. Geophys. Union, 81, 13-16, 2000.

ESKINAZI-LEÇA, E.; KOENING, M. L; SILVA-CUNHA, M. Da G. G. da. Estrutura e dinâmica da comunidade fitoplanctônica. In: ESKINAZI-LEÇA, E.; NEUMANN-LEITÃO, S.; COSTA, M. F. (Org.). Oceanografia - Um cenário tropical. Recife: Bagaço, 2004a. p. 353-373.

ESTRADA, M.; VARELA, L. A.; SALAT, J.; CRUZADO, A.; ARIAS. E. Spacio-temporal variability of Summer phytoplankton distribution across the Catalan and North Balearic Fronts (NW Mediterranean). Journal of Plankton Research, [S.1.], v. 21, n. 1, p. 1-20, 1999.

FEITOSA, F. A. do N.; SILVA-CUNHA, M. da G. G. da; PASSAVANTE, J. Z. de O.; NEUMANN-LEITÃO, S.; LINS, I. C. Estrutura do microfitoplâncton no sistema estuarino do rio Goiana, Pernambuco, Brasil. Trabalho Oceanográfico [da] Universidade Federal de Pernambuco, Recife, v. 27, n. 2, p. 1-13, 1999.

GRAHAM, L. E.; WILCOX, L. W. Algae. New Delhi: Prentice Hall, 640 p. 2000. GRASSOHOFF, K.; EHRARDT, M.; KREMELING, K. Methods of sea water analysis. 2 ed. New York: Verlag Chemie, 1983. 317 p.

GUERRA, A. T. Dicionário geológico - geomorfológico. Rio de Janeiro: IBGE, 1969. 439 p.

Tropical Oceanography, Recife, v. 33, n. 2, p. 163-181, 2005. 
HENDEY, N. I. An introductory accorent of the smaller algae of British coastal water. London: Fishery Investigations, 1964. 90 p. (Ministry of Agriculture, Fisheries and Food; Fishery Investigations Series IV; pt. 4: Bacillariophyceae - Diatoms).

HEURCK, H. van. A treatise on the diatomaceae. London: Willian Wesley, 1986. 559 p. HOEK, C.; MANN, D. G. JAHNS, H. M. Algae: an introduction to phycology. Cambridge University Press, Cambridge, 1995. 623p.

HONORATO da SILVA, M. Fitoplâncton do estuário do rio Formoso (Rio Formoso, Pernambuco, Brasil): biomassa, taxonomia e ecologia. 2003. 130 f. Dissertação (Mestrado em Oceanografia) - Departamento de Oceanografia, Universidade Federal de Pernambuco, Recife, 2003.

HUSTEDT, F. Die Kieselalgen. Deutschlands, Österreichs und der Schweiz unter Berücksichtigung der übrigen Länder Europas sowie der angrenzenden Meeresgebiete. Leipzig: Akademische Verlagsgesellschaft Geesr \& Portig K-G. 1930. 920 p. (L. Rabenhorst, Kryptogamen-Flora von Deutschland, Österreich und der Schweiz, v. 7, pt. 1).

HUSTEDT, F. Die Kieselalgen. Deutschlands, Österreichs und der Schweiz unter Berücksichtigung der übrigen Länder Europas sowie der angrenzenden Meeresgebiete. Leipzig: Akademische Verlagsgesellschaft Geesr \& Portig K-G. 1959. 920 p. (L. Rabenhorst, Kryptogamen-Flora von Deutschland, Österreich und der Schweiz, v. 7, pt. 2, n. 1-6).

HUSTEDT, F. Die Kieselalgen. Deutschlands, Österreichs und der Schweiz unter Berücksichtigung der übrigen Länder Europas sowie der angrenzenden Meeresgebiete. Leipzig: Akademische Verlagsgesellschaft Geesr \& Portig K

KOENING, M. L.; ESKINAZI-LEÇA, E. Aspectos quantitativos do fitoplâncton na área estuarina de Suape (Pernambuco). In: ENCONTRO BRASILEIRO DE PLÂNCTON, 4., 1990, Recife. Anais... Recife: UFPE, 1991. p. 55-60.

KOENING, M. L.; ESKINAZI-LEÇA, E.; NEUMANN-LEITAO, S. et al. Impactos da construção do Porto de Suape sobre a comunidade fitoplanctônica no estuário do rio Ipojuca (PernambucoBrasil). Acta Botanica Brasilica, [S.1.], v.16, n.4, p.407-420, 2002.

KOENING, M. L.; ESKINAZI-LEÇA, E.; NEUMANN-LEITAO, S. et al. Impactos da construção do Porto de Suape sobre a comunidade fitoplanctônica no estuário do rio Ipojuca (PernambucoBrasil). Acta Botanica Brasilica, [S.1.], v.16, n.4, p.407-420, 2002.

KREBS, C. J. The experimental analysis of distribution and abundance. New York: Harper \& Row, 1984. p.433-700. Cap.: Distribution and abundance at the community level.

LIMA, D. C. C. Delimitação da linha de costa atual e zoneamento da faixa litorânea como contribuição à gestão costeira do município de Tamandaré, Pernambuco - Brasil. 2001. $54 \mathrm{f}$. Monografia (Especialização em Gestão de Ambientes Costeiros Tropicais) - Departamento de Oceanografia, Universidade Federal de Pernambuco, Recife, 2001.

LOBO, E.; LEIGHTON, G. Estructuras comunitarias de las fitocenosis planctônicas de los sistemas de desembocaduras de rios y esteros de la zona central de Chile. Revista Biologia Marina, [S.1.], n. 22, p. 1-29, 1986.

Tropical Oceanography, Recife, v. 33, n. 2, p. 163-181, 2005. 
MATEUCCI, S. D.; COLMA, A. La metodologia para el estudo de la vegetácion. Collection de Monografias Cientificas, [S.1.]., n. 22, 1982, 168 p. (Série Biologia).

MELO, U.; SUMMERHAYES, C. P.; TONER, L. G. Metodologia para o estudo do material em suspensão na água do mar. Boletim Técnico da Petrobrás, Rio de Janeiro, v. 18, n.3/4, p. 115.

MOREIRA FILHO, H.; VALENTE-MOREIRA, I. M.; SOUZA-MOSMANN, R. M.; CUNHA, J. A. Avaliação florística e ecológica das Diatomáceas (Chrysophyta - Bacillariophyceae) marinha e estuarinas nos Estados do Paraná, Santa Catarina e Rio Grande do Sul. Estudos de Biologia, Curitiba, v. 25, p. 5-48, 1990.

MOURA, R. T. de. Biomassa, produção primária do fitoplâncton e alguns fatores ambientais na Baía de Tamandaré, Rio Formoso, Pernambuco, Brasil. 1991. 290 f. Dissertação (Mestrado em Oceanografia Biológica) - Departamento de Oceanografia, Universidade Federal de Pernambuco, Recife, 1991.

MUKAI, T.; TAKIMOTO, K. Effects of environmental gradients concerning water qualities on the structure oh the phytoplankton community in the coastal sea. Estuarine, Coastal and Shelf Science, London, v. 20, p.169-181, 1985.

NASCIMENTO-VIEIRA, D. A. Macrozooplâncton Recifal da Baía de Tamandaré, Pernambuco - Brasil). 2000. 107 f. Tese (Doutorado de Oceanografia) - Departamento de Oceanografia, Universidade Federal de Pernambuco, Recife, 2000.

PERAGAlLO, H.; PERAGALlO, M. Diatomées marines de France et des districtes maritimes voisins. Paris: M. J. Tempère, 1897-1908, , 137 p. Reimprimé 1967. 2 v.

SECTMA. Secretaria de Ciência, tecnologia e Meio ambiente. Atlas da Biodiversidade de Pernambuco. Recife: SCTM, 2002. 86 p.

PHLIPS, J. E.; BADYLAK, S; GRASSKOPF. Factors Affecting the Abundance of Phytoplankton in a Restricted Subtropical Lagoon, the Indian River Lagon. Estuarine, Coastal and Shelf Science, London, v. 55, p. 385-402, 2002.

POOLE, H. H.; ATKINS, W. R. G. Photo-eletric measurements of submarine illumination through the year. Journal of Marine Biological Association of the United Kingdom, London, v. 16, p. 297-324, 1929.

PUIGSERVER, M.; RAMON, G.; MOYA, G. Spatial and Temporal Distribution of Phytoplankton in a Mediterranean Estuarine Canal System. Journal of Coastal Research. Florida, v. 18, n. 1, p. 39-51, 2002.

REBOUÇAS, A. C. Sedimentos da Baía de Tamandaré - PE. Trabalhos do Instituto Oceanográfico [da] Universidade Federal de Pernambuco, Recife, v. 7/8, p. 151-185, 1965/1966.

RILEY, G. A. The plankton of estuaries. In: LAUFF, G. H. (Ed.). Estuaries. Washington: American Association Advancement Science, 1967. p. 316

Tropical Oceanography, Recife, v. 33, n. 2, p. 163-181, 2005. 
ROSEVEL SILVA, M.; SILVA-CUNHA, M. da G. G. da; FEITOSA, F. A. do. Nascimento.

Distribuição da flora planctônica na confluência estuarina dos rios Ilhetas e Mamucaba, relacionada com algumas variáveis ambientais (Tamandaré, Pernambuco, Brasil). In: JORNADA DE ENSINO, PESQUISA E EXTENSÃO, 4., 2004a, Recife. Anais... Recife: UFRPE, 2004a. CD-ROM.

ROSEVEL SILVA, M.; SILVA-CUNHA, M. G. G.; FERREIRA, L. C. Aspectos qualiquantitativos do fitoplâncton em uma variação nictemeral na porção central do Canal de Santa Cruz - Itamaracá - Pernambuco. In: JORNADA DE ENSINO, PESQUISA E EXTENSÃO, 4., 2004b, Recife. Anais... Recife: UFRPE, 2004b. CD-ROM.

SATÔ, S.; PARANAGUÁ, M. N.; ESKINAZI, E. On the mecanism of redtide of Trichodesmium in Recife Northeastern Brazil, with some considerations of the relation to the human desease,

"Tamandaré fever". Trabalho do Instituto Oceanográfico [da] Universidade do Recife, Recife, v. 5/6, p. 7-49, 1963/1964.

SHANNON, L. E. A mathematical theory of communication. Bulletin of System Tecnology Journal, [S.1.], v. 27, p. 379-493, 1948.

SILVA-CUNHA, M. da G. G. da; ESKINAZI-LEÇA, E. Catálogo das Diatomáceas (Bacillariophyceae) da Plataforma Continental de Pernambuco. Recife: SUDENE, 1990. 318 p.

SOURNIA, A. Cycle annuel du phytoplancton et de la prooduction primaire dans lês mers tropicales. Marine Biology, Heidelberg, v. 3, n. 4, p. 287-303, 1969.

STRICKLAND, J. D. H.; PARSONS, T. R. A practical handbook of seawater analysis. Bulletin Fisheries Research board of Canada, Ottawa, n. 167, 1972. p. 1-205.

TUNDISI, J. G. Estudos ecológicos do fitoplâncton marinho e lacustre no Brasil. In: BICUDO, C. E. M.; TEIXEIRA, C.; TUNDISI, J. G. (Ed.) Algas: a energia do amanhã. São Paulo: [s.n.], 1986. p. 27

TUNDISI, J. G. Produção primária "standing stock" e fracionamento do fitoplâncton na região lagunar de Cananeia. São Paulo. 1969. 130 p. Tese (Doutorado em Oceanografia) Faculdade de Ciências e Letras, Universidade de São Paulo, São Paulo, 1969.

TUREKIAN, K. K. Oceanos. São Paulo: Edgar Blucher, 1969. 151p.

UNESCO. International Oceanographic Table. Wormly: Optichrome, 1973. 141 p. v. 2.

VALIELA, I. Marine ecological processes. 2. ed. New York: Springer-Verlag, 1995. 686 p. 